\title{
Anatomical variations of the vascular supply of the cutaneous component of the serratus anterior myocutaneous flap: a systematic review
}

\author{
C. Gakis ${ }^{1}$, D. Chrysikos ${ }^{1}$, A. Samolis ${ }^{1}$, V. Protogerou ${ }^{1}$, G. Tsourouflis ${ }^{2}$, T. Troupis ${ }^{1}$ \\ ${ }^{1}$ Department of Anatomy, School of Medicine, National and Kapodistrian University of Athens, Greece \\ ${ }^{2}$ Second Department of Propaedeutic Surgery, Medical School, National and Kapodistrian University of Athens, Greece
}

[Received: 6 September 2021; Accepted: 13 October 2021; Early publication date: 26 October 2021]

\begin{abstract}
Although appealing from a reconstructive standpoint, the incorporation of the overlying skin in a serratus anterior muscle flap has not yet seen widespread use, due to considerations with its blood supply. In the present study, a systematic review of the literature has been performed, evaluating studies that investigated the vascular anatomy and variations of serratus anterior myocutaneous flap. The anatomy of the cutaneous blood supply, the size of the cutaneous territory, the design of the skin paddle and the reconstructive goals were analysed. The results showed that the main blood supply originates from the intramuscular anastomoses between intercostal artery perforators and the serratus artery branch in the form of choke vessels. Complementary perfusion from true intramuscular vessel anastomoses or from direct serratus artery cutaneous perforators could contribute to the skin blood supply but only in 25\% of the cases. The design of the flap is elliptical with its long axis over the harvested muscle slips and maximum width is 6-8 cm. A myocutaneous serratus anterior flap could be applied in a variety of reconstructive fields, most commonly for head and neck defects. A delay procedure would considerably enhance the perfusion of the cutaneous component and improve the overall viability of the flap. (Folia Morphol 2022; 81, 4: 834-842)
\end{abstract}

Key words: serratus anterior, flap skin, cutaneous component, blood supply

\section{INTRODUCTION}

Myocutaneous flaps, flaps consisting of muscle and their overlying skin, are frequently used in reconstructive surgery, especially when large tissue bulk is required. When a skin island is transposed, attached to the underlying muscle, the subdermal vascular plexus is discontinued. Cutaneous blood supply then stems from perforator vessels, arteries and accompanying veins that arise from the muscle surface [2]. This kind of cutaneous blood supply is very reliable in body areas where muscles and overlying skin are firmly connected, such as latissimus dorsi muscle, but becomes questionable when skin and muscle are loosely attached together, such as serratus anterior [4].

\section{Embryology}

Serratus anterior muscle belongs to the superficial thoracic muscles. Its origin and development is different from those of limb muscles. It is believed

Address for correspondence: Prof. T. Troupis, Department of Anatomy, School of Medicine, Faculty of Health Sciences, National and Kapodistrian University of Athens, 75 Mikras Asias str., Goudi, 11527 Athens, Greece, tel: +30-210-7462388, fax: +30-210-7462398,

e-mail: ttroupis@med.uoa.gr

This article is available in open access under Creative Common Attribution-Non-Commercial-No Derivatives 4.0 International (CC BY-NC-ND 4.0) license, allowing to download articles and share them with others as long as they credit the authors and the publisher, but without permission to change them in any way or use them commercially. 
that it is formed from myotomes but its exact origin is not certain, and it is not clarified how myotome cells attach to the scapula to create this muscle. At first, in the $9 \mathrm{~mm}$ embryo it resembles a premuscle mass with any attachments neither to the scapula nor to the ribs. It becomes more defined and attaches with digitations to the ribs in the $11 \mathrm{~mm}$ embryo. Finally it develops to its adult form with insertion into the scapula in the $14 \mathrm{~mm}$ embryo $[11,19,26]$.

\section{Surgical anatomy}

Serratus anterior muscle is a fan shaped muscle, originating from the upper 8 to 9 ribs at the lateral chest wall, which inserts into the superior angle, the medial border and the inferior angle of the scapula. Its blood supply stems from the superior thoracic artery, the lateral thoracic artery and the serratus artery branch of the thoracodorsal artery. The latter perfuses the inferior part of the muscle which is commonly used as a free or pedicled flap [11].

A serratus anterior myocutaneous flap, although first reported in 1982 [21], has not yet seen widespread use due to considerations with the viability of the cutaneous component. It was even considered unacceptable to include the overlying skin, because until then a direct communication of the cutaneous perforators with the serratus arterial network had yet not been identified [12].

An anatomic investigation of the cutaneous blood supply over the muscle and its relation with the arterial axis of the serratus anterior flap, the definition of the shape and size of the flap and the possible technical pitfalls, would delineate the likelihood of harvesting a myocutaneous flap, which would be a useful option in the armamentarium of a reconstructive surgeon.

\section{MATERIALS AND METHODS}

\section{Search strategy}

This systematic review was performed in accordance with the Preferred Reporting Items for Systematic Reviews and Meta-Analyses (PRISMA) guidelines. The protocol of this systematic review has been submitted to the Institutional Review Board of Department of Anatomy, National and Kapodistrian, University of Athens, Greece, and is available upon request. Eligible articles were identified by a search of the Medline, the Cochrane Library and the Google Scholar bibliographical databases for the period from April 1982 up to May 2019. The study protocol was agreed by all co-authors. The search strategy included the following keywords: ("serratus anterior flap" OR "skin" OR "cutaneous" OR "myocutanous" OR "musculocutaneous" AND ['anatomical variants' OR 'anomalies']). Language restrictions were applied (only articles in English, French, and German were considered eligible). Two investigators (C.G. and D.C.), working independently, searched the literature and extracted data from each eligible study. Reviews were not eligible, while all prospective and retrospective studies, as well as case reports, were eligible for this systematic review. Manuscripts that did not state the names of the authors were excluded. Case reports of a serratus anterior flap with a cutaneous component without an anatomic investigation of the skin blood supply were also excluded. In addition, we checked all the references of relevant reviews and eligible articles that our search retrieved, so as to identify potentially eligible conference abstracts. Titles of interest were further reviewed by abstract. Finally, reference lists of eligible studies were manually assessed in order to detect any potential relevant article ("snowball" procedure).

The literature review resulted in 10 relevant anatomical studies. Data was collected and analysed based on the anatomic basis of the cutaneous blood supply, the cutaneous island dimensions (theoretical in cadavers and applied in patients), the suggested design of a myocutaneous flap and the defect area where each one of them was applied on.

\section{RESULTS}

The flow chart of the study depicts that the investigated subject is not an intensively reviewed field (Fig. 1).

Four studies proved the reliance of the blood supply of the cutaneous surface on the serratus branch by a cause and effect experiment (intra-arterial dye injection caused skin staining). Additionally, these studies calculated the mean cutaneous island surface stained. Typically the procedure included the catheterisation of the thoracodorsal artery and the injection of variable volumes of a dye (methylene blue or black ink). Perrot in his study used a mixture of a dye and a radiopaque substance for radiologic co-evaluation [17]. All but one studies [9] stated that the arterial branch to latissimus dorsi muscle was ligated prior to the injection of the dye.

The calculation of the stained surface was accomplished following a computer assisted planimetric method [13], using a photo-processing software [9] 


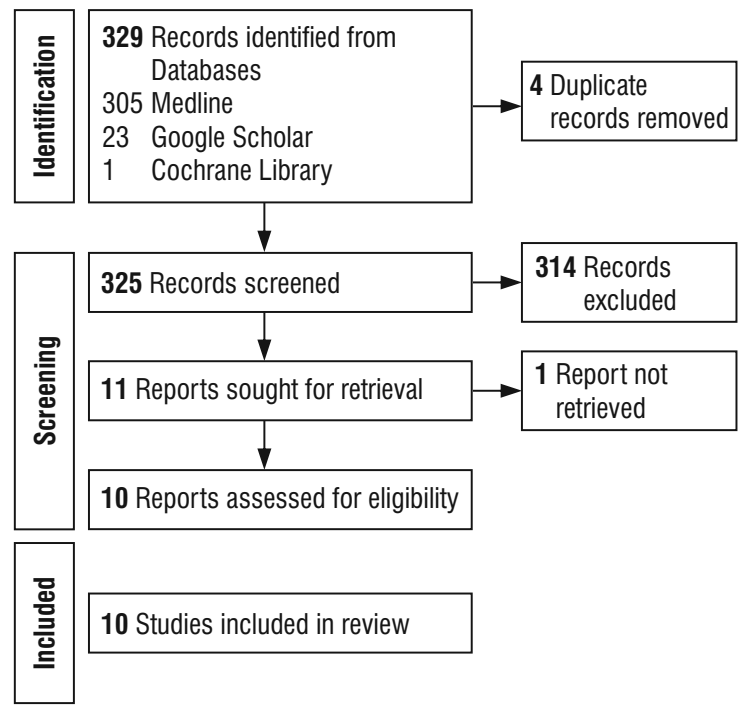

Figure 1. Flow chart.

or with a simple estimation based on length and width [21]. Estimated width ranged between 5.5 and $21 \mathrm{~cm}$, length between 6 and $20.5 \mathrm{~cm}$ and surface between 38.4 and $223.6 \mathrm{~cm}^{2}$. The boundaries of the stained skin in relation to anatomic landmarks were also taken into consideration (Table 1).

Apart from the cutaneous staining experiment, Perrot et al. [17] performed a cadaver dissection and recognized multiple cutaneous perforators arising from the muscle fascia, but did not proceed with a further investigation of their intramuscular course.
Innoue et al. [7] noticed intraoperatively multiple short muscular branches arising from the muscle fascia, during the harvest of pedicled myocutaneous serratus anterior flaps. They speculated that the surface fascia of serratus anterior muscle receives its blood supply from the thoracodorsal artery and perfuses the overlying skin through these short perforators [7].

Pittet et al. [18] in their cadaver study injected a mixture of a dye, gelatin and barium for radiologic co-evaluation. They recognized intercostal artery perforators reaching the skin, as well as giving branches to serratus anterior during their intramuscular course. However, they did not observe any anastomosis between these muscular branches and the serratus artery branch [18].

In fact, it was Godat et al.'s study [3] that uncovered an intramuscular arterial anastomosis. Following a large number of cadaver dissections, a detailed description of the vascular anatomy of the serratus anterior muscle was achieved. Contributions to the blood supply from the intercostal artery perforators were found through an intramuscular anastomosis; however, these were inconstant [3].

Hamdi et al. [5] as part of their cadaver dissection study, made a detailed mapping of the intercostal perforators in the lateral thoracic wall (number of intercostal perforators and their mean distance from the anterior border of latissimus dorsi muscle) trying to delineate the anatomy of a lateral intercostal perforator fasciocutaneous flap. In $21 \%$ of the cases, a vascular anastomosis between serratus anterior

Table 1. Surface of cutaneous staining after dye injection in cadavers

\begin{tabular}{|c|c|c|c|c|c|}
\hline Author & $\begin{array}{l}\text { Dye and injected } \\
\text { volume }\end{array}$ & $\begin{array}{l}\text { Width (mean) } \\
{[\mathrm{cm}]}\end{array}$ & $\begin{array}{l}\text { Length (mean) } \\
{[\mathrm{cm}]}\end{array}$ & $\begin{array}{c}\text { Territory (mean) } \\
{\left[\mathrm{cm}^{2}\right]}\end{array}$ & $\begin{array}{c}\text { Relation to } \\
\text { anatomic landmarks }\end{array}$ \\
\hline Bruck (12 hemithoraces) & $10 \mathrm{~mL}$ of methylene blue & Range 5.5-7 & $12-15$ & No data & $\begin{array}{l}\text { Laterally: anterior axillary line } \\
\text { Medially: not specified } \\
\text { Superiorly: } 5^{\text {th }} \text { rib } \\
\text { Inferiorly: } 7^{\text {th }} \text { rib }\end{array}$ \\
\hline Perrot (26 hemithoraces) & $\begin{array}{l}2 \mathrm{~mL} \text { of methylene blue } \\
\text { mixed with } 30 \mathrm{~mL} \\
\text { iodinated contrast }\end{array}$ & $\begin{array}{c}10.75 \\
\text { (range 9-12) }\end{array}$ & $\begin{array}{c}11.75 \\
\text { (range 10-14) }\end{array}$ & $\begin{array}{c}125 \\
\text { (range 110-140) }\end{array}$ & $\begin{array}{l}\text { Laterally: anterior axillary line } \\
\text { Medially: nipple } \\
\text { Superiorly: } 5^{\text {th }} \text { rib } \\
\text { Inferiorly: } 7^{\text {th }} \text { rib }\end{array}$ \\
\hline Mijatovic (50 hemithoraces) & $40 \mathrm{~mL}$ of black ink & No data & No data & $\begin{array}{c}143.79 \\
\text { (range } 131.8-211.4 \text { ) }\end{array}$ & Not specified \\
\hline Janik (20 hemithoraces) ${ }^{*}$ & $\begin{array}{c}40 \text { to } 60 \mathrm{~mL} \\
\text { of methylene blue }\end{array}$ & $\begin{array}{c}15.5 \\
\text { (range 10-21) }\end{array}$ & $\begin{array}{c}10.9 \\
\text { (range 6-20.5) }\end{array}$ & $\begin{array}{c}85.6 \\
\text { (range 38.4-223.6) }\end{array}$ & $\begin{array}{l}\text { Laterally: posterior axillary line } \\
\text { Medially: nipple } \\
\text { Superiorly: } 29.3 \% \text { of hemithorax } \\
\text { Inferiorly: } 51.7 \% \text { of hemithorax } \\
\text { (in craniocaudal direction } \\
\text { calculated from axilla) }\end{array}$ \\
\hline
\end{tabular}

\footnotetext{
*Janik injects thoracodorsal artery without ligating latissimus dorsi branch
} 
muscle arteries and intercostal artery perforators was found. The most frequent positions were in the $6^{\text {th }}$ $(30 \%)$ and $7^{\text {th }}(38 \%)$ intercostal spaces. Based on this finding they suggested that in the presence of that anastomosis, a serratus anterior perforator (fasciocutaneous) flap could be raised [5].

Park et al. [16] found in their study (cadaver dissection and angiography) a similar frequency of intramuscular anastomosis of the serratus anterior artery branch and intercostal perforators (25\%), although the sample in question was small. The perforators arose from the $6^{\text {th }}$ and $7^{\text {th }}$ intercostal spaces in one case and from the $4^{\text {th }}$ intercostal space in another [16].

Tamburino et al. [22] in their cadaver dissection study discovered a direct cutaneous perforator branching from the serratus artery branch in $25 \%$ of the cases. They emphasized that these perforators had no intramuscular course and lay superficial to the muscle. This perforator was found arising more frequently from the $6^{\text {th }}(33 \%)$ and $7^{\text {th }}(41.6 \%)$ intercostal spaces. In their radiologic study, occurrence was reported less frequently $(18 \%)$. The authors attributed this to the radiological protocol used, since the samples had been derived from computed tomography chest angiographies of patients suspected for pneumonic embolism. They believe that a special radiological protocol would have probably revealed more perforators (Table 2) [22].

The suggested design of the flap typically centres the axis of the flap over the selected muscle slips. Lateral border varies from 2 to $3 \mathrm{~cm}$ over the latissimus dorsi muscle to the anterior axillary line. Medial border most commonly reaches the midclavicular line but a medial extension of $2 \mathrm{~cm}$ is also described. The superior border extends to the $5^{\text {th }}$ or the $6^{\text {th }}$ rib and the inferior border to the $8^{\text {th }}$ or the $9^{\text {th }}$ rib. Maximum width is kept to $6-8 \mathrm{~cm}$ to facilitate direct closure. A different description was given by Janik et al. [9] who defined the vertical anatomic borders of the flap in relation to the height of the hemithorax. In Park et al.'s [16] study the suggested orientation of the flap is parallel to the anterior border of latissimus dorsi muscle and not to the serratus anterior (Table 3, Fig. 2).

The studies included in our review, reported 54 successful flaps with a cutaneous component. The flaps were either pedicled or free and were aimed to reconstruct defects in various anatomic areas, most commonly head and neck defects (Table 4) $[1,7-9,18,21]$.

\section{DISCUSSION}

Serratus anterior muscle flap is a useful alternative option for the reconstruction of various anatomical areas. The muscle is quite thin which makes it superior compared to other workhorse muscle flaps such as latissimus dorsi and rectus abdominis, in cases where a large muscle bulk is not desired. In cases where only the lower slips are harvested, the resulting functional deficit is negligible [27]. It is worth mentioning that the overlying skin is generally delicate and pliable. Additionally the intervening subcutaneous fat in individuals with normal body mass index is thin. The incorporation of the skin in a myocutaneous serratus anterior flap adds cosmetic superiority and durability while it allows for a shorter healing period in comparison with skin graft coverage. Flap monitoring is another convenience that a skin paddle offers. Clinical examination of a muscle flap, is not as simple as of a myocutaneous flap, and is even harder if the muscle is covered with a skin graft. Capillary refill test and flap colour estimation are easily done on a cutaneous paddle and reflect the viability of the whole flap. Monitoring of the skin island permits an early recognition of a microvascular compromise and a timely surgical reexploration. This has been shown to lead to higher salvage rates [20].

These advantages have, for the most part, encouraged the research on the cutaneous blood supply anatomy.

The skin staining observed after the injection of a dye in the thoracodorsal artery has proven that a myocutaneous flap could be perfused by this vascular axis. On the other hand, the estimation of skin surface size using this method is considered inefficient. Several small cutaneous perforators arise along the course of the thoracodorsal artery, around the anterior border of the latissimus dorsi muscle [14]. In addition a direct dominant perforator branches off the thoracodorsal artery in $55-60 \%$, with three branching patterns being reported, arising from the thoracodorsal artery $(50 \%)$, the latissimus dorsi branch (30\%) and the serratus branch $(20 \%)[6,25]$. When placing the catheter proximal to the origin of the thoracodorsal artery, these perforators are also perfused. Moreover, in the study with the biggest stained skin territory, it was not clarified whether the branch to the latissimus dorsi was ligated [12]. Through this branch the perforators arising from the latissimus dorsi muscle surface would also perfuse their overlying surface 
Table 2. Summary of anatomic studies

\begin{tabular}{|c|c|c|c|c|}
\hline Author & Type of anatomic study & $\begin{array}{c}\text { Number of } \\
\text { hemithoraces }\end{array}$ & Observations & Conclusions \\
\hline Bruck (1990) & $\begin{array}{l}\text { Fresh cadaver: dye } \\
\text { injection in TDA } \\
\text { (LD branch ligated) }\end{array}$ & 12 & $\begin{array}{l}\text { Overlying skin of SAM as well as peri- } \\
\text { osteum of } 5,6,7 \text { ribs were stained }\end{array}$ & $\begin{array}{l}\text { There is a connection between serratus } \\
\text { anterior branch and intercostal perfora- } \\
\text { tors (though not visualised) since both } \\
\text { skin and periosteum were stained }\end{array}$ \\
\hline Inoue (1991) & $\begin{array}{l}\text { Intraoperative observations } \\
\text { during myocutaneous } \\
\text { serratus anterior } \\
\text { flap harvest }\end{array}$ & 11 & $\begin{array}{l}\text { Multiple short muscular branches aris- } \\
\text { ing from muscle fascia were observed }\end{array}$ & $\begin{array}{l}\text { The carrier of the blood supply is con- } \\
\text { sidered to be the surface fascia of SAM } \\
\text { in continuity to the serratus branch of } \\
\text { the thoracodorsal artery }\end{array}$ \\
\hline Godat (2004) & $\begin{array}{l}\text { Cadaver, latex }+ \text { dye } \\
\text { injection, anatomic } \\
\text { dissection of the muscle } \\
\text { and its arterial network }\end{array}$ & 50 & \multicolumn{2}{|c|}{$\begin{array}{l}\text { There were variable intramuscular connections between serratus branch, } \\
\text { intercostal perforators and lateral thoracic artery }\end{array}$} \\
\hline Mijatovic (2006) & $\begin{array}{l}\text { Fresh cadaver: dye } \\
\text { injection in TDA } \\
\text { (LD branch ligated) }\end{array}$ & 50 & \multicolumn{2}{|c|}{ Overlying skin of SAM was stained } \\
\hline Perrot (2006) & $\begin{array}{c}\text { Fresh cadaver: dye } \\
\text { + iodized product injection } \\
\text { in TDA (LD branch ligated), } \\
\text { macroscopic and } \\
\text { radiographic evaluation }\end{array}$ & 25 & $\begin{array}{l}\text { Overlying skin of SAM was stained. } \\
\text { Multiple cutaneous perforators arising } \\
\text { from the surface fascia of the SAM } \\
\text { were observed }\end{array}$ & $\begin{array}{l}\text { The cutaneous perforators rely on the } \\
\text { blood supply of the serratus branch of } \\
\text { the thoracodorsal artery }\end{array}$ \\
\hline Pittet (2006) & $\begin{array}{l}\text { Fresh cadaver: blue dye } \\
\text { + barium + gelatin } \\
\text { injection in TDA, anatomic } \\
\text { dissection + radiographic } \\
\text { evaluation }\end{array}$ & Not mentioned & $\begin{array}{l}\text { The study confirmed the presence of: } \\
\text { (i) perforator vessels from intercostals } \\
\text { reaching the skin; } \\
\text { (ii) intercostal perforators giving } \\
\text { muscular branches }\end{array}$ & $\begin{array}{l}\text { Skin blood supply is derived from } \\
\text { perforator branches from intercostals, } \\
\text { which also give muscular branches. } \\
\text { This intramuscular connection with } \\
\text { the thoracodorsal system } \\
\text { could not be visualised }\end{array}$ \\
\hline Hamdi (2008) & $\begin{array}{l}\text { Fresh formalin } \\
\text { preserved cadavers, } \\
\text { anatomic dissection }\end{array}$ & 47 & $\begin{array}{l}\text { A vascular connection between inter- } \\
\text { costal perforators and serratus branch } \\
\text { was found in } 21 \% \text { overall, } 38 \% \text { in } \\
7^{\text {th }} \text { intercostal space, } 30 \% \text { in } 6^{\text {th }} \text { inter- } \\
\text { costal space. Dominant intercostal } \\
\text { perforators were found approximately } \\
\quad 3.5 \mathrm{~cm} \text { medial to LD }\end{array}$ & $\begin{array}{l}\text { There is only a } 21 \% \text { overall incidence of } \\
\text { vascular connection between serratus } \\
\text { branch and intercostal perforators } \\
\text { permitting the harvesting of overlying } \\
\text { skin based on TDA }\end{array}$ \\
\hline Park (2016) & $\begin{array}{l}\text { Fresh cadaver, angiography } \\
+ \text { + dissection }\end{array}$ & $\begin{array}{l}8 \text { (4 angiography, } \\
4 \text { dissection) }\end{array}$ & $\begin{array}{c}\text { A connection between intercostal } \\
\text { perforators and serratus branch via an } \\
\text { intramuscular branch was observed } \\
\text { in } 25 \%\end{array}$ & $\begin{array}{l}\text { A serratus anterior perforator flap } \\
\text { feasible in } 25 \% \text { of patients }\end{array}$ \\
\hline \multirow[t]{2}{*}{ Tamburino (2017) } & $\begin{array}{l}\text { Fresh cadaver, latex } \\
\text { injection in TDA } \\
\text { + dissection }\end{array}$ & 8 & $\begin{array}{l}\text { In } 25 \% \text { of cadaver dissections a cutane- } \\
\text { ous perforator was found arising directly } \\
\text { from the serratus branch } \\
\text { (no intramuscular course) }\end{array}$ & $\begin{array}{l}\text { A serratus anterior perforator } \\
\text { flap is possible with suitable } \\
\text { preoperative perforator mapping }\end{array}$ \\
\hline & $\begin{array}{l}\text { Computed tomography } \\
\text { chest angiographies } \\
\text { (for suspected PE) }\end{array}$ & 33 & $\begin{array}{c}\text { The 'direct' cutaneous perforator was } \\
\text { found in } 18 \% \text { (always bilaterally) } \\
\text { of the cases }\end{array}$ & \\
\hline Janik (2018) & $\begin{array}{l}\text { Fresh cadaver, dye } \\
\text { injection (LD branch } \\
\text { not ligated) }\end{array}$ & 20 & $\begin{array}{l}\text { Cutaneous staining measurement, } \\
\text { definition of anatomical landmarks }\end{array}$ & $\begin{array}{l}\text { Suggested design: superior border } \\
=29.3 \% \text { of hemithorax, inferior } \\
\text { border }=51.7 \% \text { of hemithorax (in } \\
\text { craniocaudal direction calculated } \\
\text { from axilla), posterior border not } \\
\text { passing LD, anterior border } \\
=\text { anterior axillary line }\end{array}$ \\
\hline
\end{tabular}

LD — latissimus dorsi; PE — pulmonary embolism; SAM — serratus anterior muscle; TDA — thoracodorsal artery

as well as adjacent territories. Considering the close relationship of latissimus dorsi and serratus muscles, this could lead to an overestimation of the possible cutaneous territory. Incising the perimetry of the flap to the level of the muscle fascia first, and then injecting the dye, would preclude the perfusion of the skin from perforators that do not arise from the serratus anterior muscle. 
Table 3. Suggested design

\begin{tabular}{|c|c|}
\hline Author & Suggested design \\
\hline Bruck (1990) & $\begin{array}{l}\text { Superiorly: above the } 5^{\text {th }} \text { rib } \\
\text { Inferiorly: below the } 7^{\text {th }} \text { rib } \\
\text { Laterally: anterior axillary line } \\
\text { Medially: not specified } \\
\text { Flap is centred over the } 6^{\text {th }} \text { rib } \\
5^{\text {th }}, 6^{\text {th }} \text { slips and ribs are harvested } \\
\text { Skin island is approximately } 6 \text { by } 12 \mathrm{~cm}\end{array}$ \\
\hline Inoue (1991) & $\begin{array}{l}\text { Laterally: mid-axillary line } \\
\text { Medially: hypochondrium (medial extent is the end of } \\
\text { the } 7,8 \text { slips) } \\
\text { Centred over } 7^{\text {th }}, 8^{\text {th }} \text { ribs }\end{array}$ \\
\hline Pittet (2006) & $\begin{array}{l}\text { Superiorly: inframammary crease } \\
\text { Inferiorly: } 9^{\text {th }} \text { rib } \\
\text { Laterally: anterior border of latissimus dorsi } \\
\text { Medially: } 2 \mathrm{~cm} \text { medially to midclavicular line } \\
\text { Skin paddle can be extended } 2-3 \mathrm{~cm} \text { over latissimus } \\
\text { dorsi and harvested with underlying fascia. Usually } \\
2 \text { slips of serratus harvested but no more than } 3\end{array}$ \\
\hline Park (2015) & $\begin{array}{l}\text { Long axis of flap near the anterior axillary line, } \\
\text { anterior to ant border of LD. Flap centred over } 5-7 \text { rib. } \\
\text { Width } 6-8 \mathrm{~cm} \text { to permit direct closure. Length extended } \\
\text { in fusiform fashion to facilitate closure. Distal part not } \\
\text { adequately perfused, discarded before flap inset. Caudal } \\
5-6 \text { muscle slips incorporated }\end{array}$ \\
\hline Janik (2018) & $\begin{array}{l}\text { Superiorly: within } 1 / 3-2 / 3 \text { of hemithorax } \\
\text { Inferiorly: on superior half of hemithorax } \\
\text { Laterally: posterior axillary line } \\
\text { Medially: midclavicular line }\end{array}$ \\
\hline
\end{tabular}

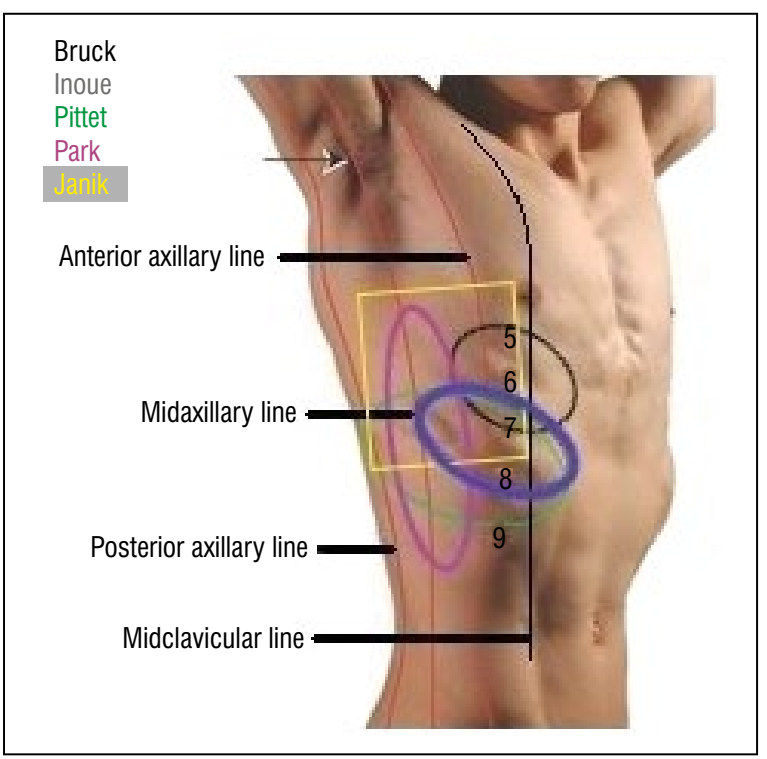

Figure 2. Suggested design.

The lateral thoracic wall has been recognized as a well perfused area receiving blood from the intercostal artery perforators [15]. Multiple reviewed anatomic studies confirmed that several intercostal artery perforators pierce the serratus anterior muscle reaching the overlying skin. Further dissection has led to recognition of intramuscular anastomoses between intercostal artery perforators and the serratus artery branch in $20-25 \%[3,5,16]$. These anastomoses were most frequently found in the $6^{\text {th }}$ and $7^{\text {th }}$ intercostal spaces (typically the $6,7,8$ serratus muscle slips overlying the $6^{\text {th }}$ and $7^{\text {th }}$ intercostal spaces are raised when harvesting a serratus anterior muscle flap). Interestingly in one study, a cutaneous perforator arising directly from the serratus artery branch, and not from the intercostal artery, was found in $25 \%$ [22]. The low consistency of these anastomoses does not however correspond to the high success rates of Pittet et al. [18] and Inoue et al. [7] (almost 90\% of complete flap survival).

A reasonable theory was reported by Pittet et al. [18]. In a cadaveric study it was recognised that intercostal artery perforators give cutaneous and muscular branches. Although an intramuscular connection between intercostal artery perforators and the serratus anterior muscle arterial network was not directly visualised in their cadaveric study, they hypothesized the existence of this connection through choke vessels. As the angiosome theory suggests, three dimensional blocks of tissue (angiosomes) are perfused by a source artery. Neighbouring angiosomes are linked with true vascular anastomosis (same vessel calibre) or with choke vessels (vessels of smaller size) [24]. Choke vessels distend to the calibre of true anastomosis in cases of blood supply insufficiency, such as when a flap is delayed, with a peak effect after 2 to 3 days [23]. A clinical indication of the existence of these choke vessels in the case series of Pittet et al. [18] was that immediately postoperatively, no cutaneous perforators of the myocutaneous flaps were traceable with a Doppler examination. They became progressively audible, suggesting the opening of the choke vessels. It is likely that the reviewed anatomic studies have not recognised these choke vessels because of their minor diameter.

In cases where a preoperative recognition of a direct cutaneous perforator is not feasible, as suggested by Tamburino et al. [22], a reasonable approach would be to delay the flap in order to enhance its vascularity. Flap delay is a preliminary procedure of incompletely raising a flap, thus partially obscuring its blood supply. During the delay period, choke vessels are allowed to dilate and as a result the flap becomes 
Table 4. Summary of successful flaps

\begin{tabular}{|c|c|c|c|c|c|c|c|}
\hline No & Author & $\begin{array}{c}\text { Free }(\mathbf{F}) / \\
\text { /Pedicled (P) }\end{array}$ & Composition & Slips & Length & Width & Reconstruction site/purpose \\
\hline 1 & Takayanagi & $\mathrm{F}$ & Myocutaneous & $5,6,7,8$ & 11 & 7 & Foot \\
\hline 2 & Bruck & $\mathrm{F}$ & Osteomyocutaneous & 5,6 & 12 & 7 & Foot \\
\hline 3 & Inoue & $P$ & Myocutaneous & $6,7,8$ & 14 & 7 & Oral cavity \\
\hline 4 & Inoue & $P$ & Myocutaneous & 7,8 & 20 & 10 & Cervical oesophagus \\
\hline 5 & Inoue & $P$ & Myocutaneous & $6,7,8$ & 14 & 7 & Tempo-auricular skin \\
\hline 6 & Inoue & $P$ & Myocutaneous & 8 & 14 & 7 & Cheek soft tissue \\
\hline 7 & Inoue & $P$ & Myocutaneous & $6,7,8$ & 14 & 7 & Oral cavity \\
\hline 8 & Inoue & $P$ & Myocutaneous & $6,7,8$ & 15 & 7 & Cervical oesophagus \\
\hline 9 & Inoue & $P$ & Myocutaneous & $6,7,8$ & 15 & 7 & Cervical oesophagus \\
\hline 10 & Inoue & $P$ & Myocutaneous & $6,7,8$ & 12 & 6 & Oral cavity \\
\hline 11 & Inoue & $P$ & Myocutaneous & $6,7,8$ & 15 & 7 & Oral cavity \\
\hline 12 & Inoue & $P$ & Myocutaneous & $6,7,8$ & 22 & 10 & Cervical oesophagus \\
\hline 13 & Pittet & $\mathrm{F}$ & Myocutaneous & $6,7,8$ & 12 & 5 & Noma, cheek, oral lining \\
\hline 14 & Pittet & $\mathrm{F}$ & Myocutaneous & $7,8,9$ & 12 & 6.5 & Noma, cheek, upper lip, inferior eyelid \\
\hline 15 & Pittet & $\mathrm{F}$ & Myocutaneous & $6,7,8,9$ & 5 & 8 & Noma, cheek, oral lining \\
\hline 16 & Pittet & $\mathrm{F}$ & Myocutaneous & $7,8,9$ & 9 & 4.5 & Noma, cheek, oral lining \\
\hline 17 & Pittet & $\mathrm{F}$ & Osteomyocutaneous & 7,8 & 8 & 6 & Noma, cheek, mandible, oral lining \\
\hline 18 & Pittet & $\mathrm{F}$ & Myocutaneous & $7,8,9$ & 15 & 6 & Noma, cheek, upper lip, oral lining \\
\hline 19 & Pittet & $\mathrm{F}$ & Osteomyocutaneous & 7,8 & 12 & 6 & Noma, maxilla, upper lip, cheek, oral lining \\
\hline 20 & Pittet & $\mathrm{F}$ & Myocutaneous & $7,8,9$ & 12 & 5 & $\begin{array}{c}\text { Noma, cheek, oral lining, } \\
\text { upper lip, nose }\end{array}$ \\
\hline 21 & Pittet & $\mathrm{F}$ & Myocutaneous & $7,8,9$ & 11 & 5 & Trauma, cheek, inferior lid \\
\hline 22 & Pittet & $\mathrm{F}$ & Osteomyocutaneous & $6,7,8$ & 10 & 5.5 & Noma, maxilla, upper lip \\
\hline 23 & Pittet & $\mathrm{F}$ & Myocutaneous & $6,7,8$ & 9 & 5 & Noma, cheek, nose, inferior eyelid \\
\hline 24 & Pittet & $\mathrm{F}$ & Myocutaneous & 7,8 & 12 & 6 & Noma, cheek, oral lining \\
\hline 25 & Pittet & $\mathrm{F}$ & Osteomyocutaneous & $7,8,9$ & 9 & 7 & $\begin{array}{l}\text { Neoplasm, lower cheek, } \\
\text { pharynx, mandible }\end{array}$ \\
\hline 26 & Pittet & $\mathrm{F}$ & Myocutaneous & 7,8 & 12 & 8 & Noma, lower lip, chin \\
\hline 27 & Pittet & $\mathrm{F}$ & Myocutaneous & $7,8,9$ & 8 & 4.5 & Noma, cheek, oral lining \\
\hline 28 & Pittet & $\mathrm{F}$ & Myocutaneous & 7,8 & 12 & 5.5 & Noma, cheek, oral lining \\
\hline 29 & Pittet & $\mathrm{F}$ & Myocutaneous & $7,8,9$ & 9 & 7 & Noma, cheek \\
\hline 30 & Pittet & $\mathrm{F}$ & Myocutaneous & 7,8 & 11 & 6.5 & Noma, cheek, oral lining \\
\hline 31 & Pittet & $\mathrm{F}$ & Myocutaneous & $7,8,9,10$ & 14 & 7 & Noma, cheek, upper lip, oral lining \\
\hline 32 & Pittet & $\mathrm{F}$ & Myocutaneous & 7,8 & 11 & 6.5 & Noma, cheek, oral lining \\
\hline 33 & Pittet & $\mathrm{F}$ & Myocutaneous & 7,8 & 7 & 5 & $\begin{array}{l}\text { Noma, cheek, upper lip, } \\
\text { commissure, oral lining }\end{array}$ \\
\hline 34 & Pittet & $\mathrm{F}$ & Myocutaneous & 7,8 & 7.5 & 6.5 & Noma, chin, lower lip, oral lining \\
\hline 35 & Pittet & $\mathrm{F}$ & Myocutaneous & $7,8,9$ & 8 & 5 & Noma, cheek, nasal lining \\
\hline 36 & Pittet & $\mathrm{F}$ & Myocutaneous & 7,8 & 6.5 & 6 & Noma, upper lip, commissure, maxilla \\
\hline 37 & Perrot & $\mathrm{F}$ & Osteomyocutaneous & $10 \times 8$ (muscle) & 4 & 4 & Inferior $1 / 3$ tibia \\
\hline 38 & Perrot & $\mathrm{F}$ & Osteomyocutaneous & $14 \times 10$ (muscle) & 6 & 4 & Inferior $1 / 3$ tibia \\
\hline 39 & Perrot & $\mathrm{F}$ & Osteomyocutaneous & $13 \times 10$ (muscle) & 5 & 3 & Inferior $1 / 3$ tibia \\
\hline 40 & Perrot & $\mathrm{F}$ & Osteomyocutaneous & $18 \times 11$ (muscle) & 5 & 4 & Inferior $1 / 3$ tibia \\
\hline 41 & Perrot & $\mathrm{F}$ & Osteomyocutaneous & $18 \times 6$ (muscle) & 6 & 3 & Inferior $1 / 3$ tibia \\
\hline 42 & Perrot & $\mathrm{F}$ & Myocutaneous & $13 \times 9$ (muscle) & 5 & 3 & Inner surface of foot \\
\hline 43 & Perrot & $\mathrm{F}$ & Myocutaneous & $14 \times 10$ (muscle) & 5 & 3 & Inner surface of knee \\
\hline 44 & Perrot & $\mathrm{F}$ & Myocutaneous & $13 \times 9$ (muscle) & 5 & 4 & Anterior carpal surface \\
\hline 45 & Janik & $\mathrm{F}$ & Myocutaneous & No data & 10 & 9 & Laryngopharyngectomy \\
\hline 46 & Janik & $\mathrm{F}$ & Myocutaneous & No data & 7 & 7 & Laryngopharyngectomy \\
\hline 47 & Janik & $\mathrm{F}$ & Myocutaneous & No data & 9 & 9 & Laryngopharyngectomy \\
\hline $48-54$ & $\begin{array}{c}\text { Janik } \\
\text { (series of } 7 \text { flaps) }\end{array}$ & $\mathrm{F}$ & Myocutaneous & No data & $\begin{array}{c}8.7 \\
\text { (mean) }\end{array}$ & $\begin{array}{c}6.7 \\
\text { (mean) }\end{array}$ & $\begin{array}{l}\text { Reconstruction after } \\
\text { salvage glossectomy }\end{array}$ \\
\hline
\end{tabular}

Only flaps with complete survival were included. Perrot (Muscle dimensions are mentioned but not which slips are taken. Cutaneous island was harvested intentionally small just for flap monitoring). 
more tolerant to relevant ischaemia. That process is extremely beneficial to the surgical outcome [10].

Serratus anterior is a thin muscle. For that reason, the point of bifurcation of the intercostal artery perforator to a muscular and a cutaneous branch would not be far from its undersurface. This bifurcation would be susceptible to thermal injury from heat dissipation, if a cautery was uncontrollably used. In that case, blood would not be allowed to run in a retrograde fashion, (serratus artery branch-choke vessels-muscular branch of intercostal perforator-cutaneous branch of intercostal perforator) resulting in flap failure. From a clinical standpoint, it should be noted that Pittet et al. [18] in their surgical technique description highlighted that they paid attention not to damage the intercostal artery perforators with the cautery [18]. Most likely their meticulous harvesting technique preserves greater number of intercostal artery perforators, therefore achieving high success rates. Consequently it would be advisable to avoid using a monopolar cautery in the undersurface of the serratus anterior muscle. Instead bipolar cautery or ligaclips should be used to isolate the perforators.

When the proposed flap designs were compared, homogeneity was observed. The flaps are commonly oriented over the muscle slips to be used with slight differences in their medial and lateral extent. On the contrary, Park et al. [16] position the long axis of the flap almost vertically against the serratus anterior muscle. Five to six muscle slips are incorporated compared to authors who only harvest two or three [16]. Although not mentioned in this study, harvesting more muscle slips could have possibly impaired function in a greater degree. That would be a concern when dealing with reconstruction in young, active individuals.

\section{CONCLUSIONS}

Serratus anterior myocutaneous flap is a useful option for reconstruction in various anatomical sites.

The intramuscular anastomoses of intercostal artery perforators with the serratus artery branch, in the form of choke vessels, is the basis of cutaneous blood supply, while direct serratus artery cutaneous perforators and true anastomoses of same size vessels contribute in a less predictable manner, in almost $25 \%$ of the cases.

Flap delay and meticulous dissection with avoidance of cautery induced damage to the intercos- tal artery perforators, are considered important for a successful outcome.

\section{Conflict of interest: None declared}

\section{REFERENCES}

1. Bruck JC, Bier J, Kistler D. The serratus anterior osteocutaneous free flap. J Reconstr Microsurg. 1990; 6(3): 209-213, doi: 10.1055/s-2007-1006820, indexed in Pubmed: 2292781.

2. Carvey M, Yang G, Hage R. Skin flaps: A novel approach to medical student instruction on integumentary arterial blood supply. Trans Res Anat. 2021; 23: 100104, doi: 10.1016/j.tria.2020.100104

3. Godat DM, Sanger JR, Lifchez SD, et al. Detailed neurovascular anatomy of the serratus anterior muscle: implications for a functional muscle flap with multiple independent force vectors. Plast Reconstr Surg. 2004; 114(1): 21-30, doi: 10.1097/01.prs.0000129072.11466.c3, indexed in Pubmed: 15220562.

4. Gurtner G, Neligan P. Plastic Surgery: Volume 1: Principles, 3rd Ed. Elsevier 2013.

5. Hamdi M, Spano A, Landuyt KV, et al. The lateral intercostal artery perforators: anatomical study and clinical application in breast surgery. Plast Reconstr Surg. 2008; 121(2): 389-396, doi: 10.1097/01.prs.0000298317.65296. cf, indexed in Pubmed: 18300954.

6. Heitmann C, Guerra A, Metzinger SW, et al. The thoracodorsal artery perforator flap: anatomic basis and clinical application. Ann Plast Surg. 2003; 51(1): 23-29, doi: 10.1097/01.SAP.0000054189.14799.F3, indexed in Pubmed: 12838121.

7. Inoue $\mathrm{T}$, Ueda $\mathrm{K}$, Hatoko $\mathrm{M}$, et al. The pedicled extended serratus anterior myocutaneous flap for head and neck reconstruction. Br J Plast Surg. 1991; 44(4): 259-265, doi: 10.1016/0007-1226(91)90067-t, indexed in Pubmed: 2059782.

8. Janik S, Pyka J, Stanisz I, et al. Use of the myocutaneous serratus anterior free flap for reconstruction after salvage glossectomy. Eur Arch Otorhinolaryngol. 2019; 276(2): 559-566, doi: 10.1007/s00405-018-5245-4, indexed in Pubmed: 30552516.

9. Janik SJ, Paraszti I, Hirtler L, et al. Design of skin islands for a myocutaneous serratus anterior free flap-An anatomical study and clinical implication for pharyngeal reconstruction after laryngopharyngectomy. Clin Otolaryngol. 2019; 44(3): 227-234, doi: 10.1111/coa.13257, indexed in Pubmed: 30411852.

10. Kevin C. Chung. Grabb and Smith's Plastic Surgery. Wolters Kluwer 2019.

11. Lung K, St Lucia K, Lui F. Anatomy, Thorax, Serratus Anterior Muscles. In: StatPearls [Internet]. Treasure Island (FL): StatPearls Publishing; 2021.

12. Merle M. Grandes pertes de substance de la main. In: Banzet and JM Servant (eds.). Chirurgie lastique, Reconstructive et Esthetique. aris: Flammarion, 1994. Flammarion, Paris 1994: 580.

13. Mijatović $D$, Bulić K, Dzepina I, et al. The supply of blood in the skin territory above the lower part of the serratus 
anterior muscle. Coll Antropol. 2006; 30(3): 543-547, indexed in Pubmed: 17058521.

14. Miyamoto S, Arikawa M, Kagaya Yu, et al. Septocutaneous thoracodorsal artery perforator flaps: a retrospective cohort study. J Plast Reconstr Aesthet Surg. 2019; 72(1): 78-84, doi: 10.1016/j.bjps.2018.08.026, indexed in Pubmed: 30291048.

15. Palmer JH, Taylor Gl. The vascular territories of the anterior chest wall. Br J Plast Surg. 1986; 39(3): 287-299, doi: 10.1016/00071226(86)90037-8, indexed in Pubmed: 3730674.

16. Park SO, Chang $H$, Imanishi $N$. The free serratus anterior artery perforator flap-A case report and anatomic study. Microsurgery. 2016; 36(4): 339-344, doi: 10.1002/ micr.30038, indexed in Pubmed: 26901798.

17. Perrot $P$, Duteille $F$, Leaute $F$, et al. Étude anatomique et applications cliniques des caractéristiques de la palette cutanée du lambeau libre de grand dentelé. Ann Chir Plast Esthet. 2006; 51(6): 494-498, doi: 10.1016/j. anplas.2006.02.003.

18. Pittet $B$, Mahajan AL, Alizadeh N, et al. The free serratus anterior flap and its cutaneous component for reconstruction of the face: a series of 27 cases. Plast Reconstr Surg. 2006; 117(4): 1277-1288, doi: 10.1097/01. prs.0000208297.02556.a5, indexed in Pubmed: 16582800.

19. Pu Q, Huang R, Brand-Saberi B. Development of the shoulder girdle musculature. Dev Dyn. 2016; 245(3): 342-350, doi: 10.1002/dvdy.24378, indexed in Pubmed: 26676088.

20. Stranix JT, Jacoby A, Lee ZH, et al. Skin paddles improve muscle flap salvage rates after microvascular compromise in lower extremity reconstruction. Ann Plast Surg. 2018; 81(1): 68-70, doi: 10.1097/SAP.0000000000001425, indexed in Pubmed: 29746277.
21. Takayanagi S, Tsukie T. Free serratus anterior muscle and myocutaneous flaps. Ann Plast Surg. 1982; 8(4): 277-283, doi: 10.1097/00000637-198204000-00003, indexed in Pubmed: 7092083.

22. Tamburino S, Menez T, Laloze J, et al. Free serratus anterior artery perforator flap: a case report with an anatomic and radiological study. Surg Radiol Anat. 2017; 39(8): 837-842, doi: 10.1007/s00276-017-1824-0, indexed in Pubmed: 28236131.

23. Taylor GI, Corlett RJ, Dhar SC, et al. The anatomical (angiosome) and clinical territories of cutaneous perforating arteries: development of the concept and designing safe flaps. Plast Reconstr Surg. 2011; 127(4): 1447-1459, doi: $10.1097 /$ PRS.0b013e318208d21b, indexed in Pubmed: 21460653.

24. Taylor GI, Palmer JH. The vascular territories (angiosomes) of the body: experimental study and clinical applications. Br J Plast Surg. 1987; 40(2): 113-141, doi: 10.1016/00071226(87)90185-8, indexed in Pubmed: 3567445.

25. Thomas BP, Geddes $C R$, Tang $M$, et al. The vascular basis of the thoracodorsal artery perforator flap. Plast Reconstr Surg. 2005; 116(3): 818-822, doi: 10.1097/01. prs.0000176253.42394.7c, indexed in Pubmed: 16141821.

26. Valasek $P$, Theis $S$, Krejci E, et al. Somitic origin of the medial border of the mammalian scapula and its homology to the avian scapula blade. J Anat. 2010; 216(4): 482-488, doi: 10.1111/j.1469-7580.2009.01200.x, indexed in Pubmed: 20136669

27. Whitney TM, Buncke HJ, Alpert BS, et al. The serratus anterior free-muscle flap: experience with 100 consecutive cases. Plast Reconstr Surg. 1990; 86(3): 481-491, indexed in Pubmed: 2385667. 